\title{
A Holistic Mindfulness
}

\author{
Ajahn Amaro
}

Published online: 4 January 2015

(C) Springer Science+Business Media New York 2015

\section{Introduction}

This paper is a commentary on traditional and contemporary mindfulness: finding the middle path in the tangle of concerns by Monteiro, Musten and Compson (2015). These are interesting times. Whereas as little as 10 years ago, such subjects as Buddhist meditation and mindfulness were confined to a specialist fringe of society, now these are so commonplace as to become the substance of a series of UK parliamentary enquiries. The most recent, at the time of writing, addressed the selfsame issues as discussed by Monteiro et al. (2015) (see Halliwell 2014).

The interest in mindfulness and its introduction into the areas of health care, education, business, and the military is increasing at an exponential rate. It is an accelerating aggregate of systems, and as such, it is delicately balanced between rapid beneficial progress and destructive implosion. On account of this escalation of interest, the field lends itself to careful scrutiny and to exploration of what within it is supportive of long-term well-being and what is extraneous or obstructive.

As a contemplative monastic functioning largely outside the academic field, and therefore hailing from the more "traditional" camp, there are perspectives that come from this background that can perhaps shed useful light on several areas outlined in (Monteiro et al. 2015), such as (1) the pragmatic versus dogmatic approach of the Buddha in his teachings on psychological transformation, (2) clarification of the traditional understanding of the term "mindfulness" (sati) and its various

\footnotetext{
A. Amaro $(\bowtie)$

Amaravati Buddhist Monastery, St Margarets Lane, Great Gaddesden, Hemel Hempstead, Hertfordshire HP1 3BZ, UK

e-mail: ajahn.amaro@gmail.com
}

layers of meaning, and (3) the role of ethics in human wellbeing, as it is understood from a traditional Buddhist viewpoint.

The perspectives offered here should not be considered definitive or exhaustive in terms of commenting on Monteiro et al. (2015) specifically or the field of mindfulness in general; rather the issues outlined in this paper are those that appear most in need of clarification, from a traditional standpoint, and the elucidation of which is likely to bring a greater understanding of the field of mindfulness practice and the benefits that derive from it.

\section{Philosophical Roots of Mindfulness Practice}

The Four Noble Truths

It has been propounded that "the basic scheme of four truths... mirrors a diagnostic scheme apparently employed in Indian medicine" (Analayo 2011). The pattern employed being as follows:

1. Symptom $=$ dissatisfaction $($ dukkha $)$

2. Cause $=$ craving $(\tanh \bar{a})$

3. Prognosis $=$ ending of dissatisfaction (dukkha-nirodha $)$

4. Treatment $=$ the Eightfold Path (a hangika magga $)$

This simple formulation points to the Buddha taking a radically pragmatic, rather than dogmatic, approach toward spiritual life and the development of well-being. Instead of using the more customary tactic of spiritual teachers, making declarative statements lauding the truth and virtues of an ultimate reality, he started with the everyday experience of dissatisfaction, suffering. Moreover, he approached it with the attitude of a clinician - "Where does it hurt?"-rather than a theoretician-"Let me tell you how it all works." 
This pragmatic approach is echoed in Monteiro et al. (2015) (p. 3) where the limbs of the Eightfold Path are described as: "'Right' insofar as they lead toward this realization [of the cessation of suffering]." This points to the understanding that it is the experience of the individual that is the defining factor, rather than any received religious ideal. This principle is articulated most clearly in the Kalama Sutta where the Buddha encourages his listeners:

"Kalamas, do not go upon what has been acquired by repeated hearing; nor upon tradition; nor upon rumour; nor upon a scripture; nor upon deduction; nor upon an axiom; nor upon dubious reasoning; nor upon a bias toward a notion that has been pondered; nor upon another's apparent ability; nor upon the consideration, 'This is our guru.' Kalamas, when you yourselves know: 'These things are unwholesome; these things are blameworthy; these things are criticized by the wise; undertaken and followed, these things lead to harm and dissatisfaction,' then you would be wise to abandon them... And when you yourselves know: 'These things are wholesome; these things are not blameworthy; these things are praised by the wise; undertaken and followed, these things lead to benefit and happiness,' you would be wise to enter upon and dwell in them." (A 3.65)

This encouragement of the Buddha accords well with the comment in Monteiro et al. (2015) (p. 3), that: "Buddhist traditions offer a course of training that helps to align one's conduct in accordance with this structure of reality and attain liberation from suffering, but there is no reason in principle why familiarity with explicitly 'Buddhist' teachings are a necessary condition for such liberation. This perspective that the outcome of the training transcends Buddhist teachings becomes particularly important to understanding the ways in which mindfulness has been adapted for secular applications." In the same way, it does not matter what the name or nationality of the physician is, or even the medical approach they use, if the sickness is cured, those details are incidental (as in "the simile of the arrow" at M 63.5, and "the handful of leaves" at S 56.31).

\section{Sammā and "Right" and "Wrong"}

In Monteiro et al. (2015) (p. 11), it is stated: "It is also important to investigate the subtle ways in which the very teaching of a philosophy derived from an Eastern culture is already a propagation of a set of valued virtues or an 'actionguide' based on a different worldview." This is granted, however, it is also important to investigate those subtle influences that are already with us, in the Judeo-Christian conditioning of the West, particularly in relation to such issues as the concepts of right and wrong as well as the broader topic of ethics. This latter element will be addressed below, but here, it will be useful to look briefly at the use of the word right.

Monteiro et al. (2015) (p. 3) phrased the principle very well in stating, above: "'Right' insofar as they lead toward this realization [of the cessation of suffering]." In contrast, the use of the word right in the context of the Noble Eightfold Path can easily be assumed to mean that there is the correct and good that should be done and there is the bad and wrong which should not be done. However, the word right is being used to translate the Pāli word sammā; sammā is not just the right which is the opposite of wrong but rather has connotations of right as in "upright," "balanced," and "attuned" (Sumedho 2014b, p. 101):

Using the words 'right' and 'wrong' in relation to 'right understanding' and 'wrong understanding' is too strong I think. They're too fixed: 'This is right and that's wrong.' ... With sammädi hi, you see right and wrong - not from trying to blend them together, but through seeing them from this position of awareness so one is in harmony. One can relate to actions, speech, livelihood and responses to life through wisdom and through being aware of the appropriateness of time and place. This comes through wise intuition, through harmony, through seeing things with a sense of balance and transcendence.

Again, this approach emphasizes the pragmatic consideration, "Does this attitude, this action, alleviate suffering?" Rather than the theoretical question, "Does this experience match the picture of how I believe things to be?" It is a realistic versus an idealistic approach to the development of wellbeing.

\section{The Origins of $d u k k h a$}

It is also significant, in this same vein, to consider the etymology of the word dukkha (according to Analayo 2003, p. 244):

Dukkha is often translated as 'suffering'. Suffering, however, represents only one aspect of $d u k k h a$, a term whose range of implications is difficult to capture with a single English word. Dukkha can be derived from the Sanskrit kha, one meaning of which is 'the axle-hole of a wheel', and the antithetic prefix $d u(=d u s)$, which stands for 'difficulty' or 'badness'. The complete term then evokes the image of an axle not fitting properly into its hole. According to this image, dukkha suggests 'disharmony' or 'friction'.

Thus, when things are not attuned or balanced (sammā), the result is disharmony or friction $(d u k k h a)$, like the wheel of a bicycle being out of kilter. The understanding of these terms, and their application in practice, lends a somewhat different 
tone to an individual's appreciation of experience. They help the practitioner to reconfigure the customary absolute judgments of "good" and "bad," right and wrong, and to reflect on what needs to be adjusted in a less personal and more practical way.

\section{Mechanistic, Informed, and Holistic Mindfulness}

The word mindfulness has come to mean many things. KabatZinn (2004) defined it as, "Mindfulness means paying attention in a particular way; on purpose, in the present moment, and non-judgmentally." This definition is somewhat broad and, though useful, is open to misinterpretation or misuse. On this issue, Monteiro et al. (2015) (p. 6) commented, firstly on the implicit rather than explicit role of ethics in the teaching and practice of mindfulness: “...that this omission [of sìla] may result in concepts such as non-judgmental awareness fostering a range of negative stances from selfindulgence to passivity" and that, "This is where (in the absence of proper teacher training) a poor grasp of concepts such as bare awareness, non-judgmental awareness, non-duality, and so on are likely to misguide the participants into bypassing their experience rather than connecting with it" (Monteiro et al. 2015 p. 8).

Within the Buddhist world alone, the word mindfulness possesses a broad spectrum of meanings. The English word was chosen by Rhys Davids (1921-1925) as one of the terms to translate the Pāli word sati, and it has become the almost universally used rendering since then. It can validly be employed to refer to the simple act of recollection (it comes from the same root as the Sanskrit word $s m t i$, meaning "memory," or "that which is remembered"); it also means the act of consciously paying attention. In this respect, it matches all of the criteria named by Kabat-Zinn above, barring the adverbal quality of "non-judgmentally."

According to classical Buddhist philosophy, sati is a morally neutral quality. It can therefore be said that a squirrel jumping through the branches of a tree or a hunting cat has sati: "Before it catches the mouse, the cat is alert and focused" (Chah 2011, p. 647). The term also accurately includes the mindfulness required of a sniper. This is not to justify those actions as somehow spiritual or good; rather, it is to point to the merely mechanistic function of sati, paying attention in the present moment, on its own.

At the other end of the spectrum, one finds such statements in the scriptures as: "Mindfulness is the path to the Deathless" (Dhp 21), with the word "Deathless" meaning total spiritual emancipation or enlightenment. This points to mindfulness as being of a profound and liberating nature. Indeed, it is the very first on the Buddha's list of the Seven Factors of Enlightenment.
This range of meanings can be best understood if we consider that the term sati, or mindfulness, is commonly being used as a shorthand for three distinct psychological qualities, referred to in Pāli by different terms.

First, sati is the simple act of paying attention to an object or action. If this is taken to be the all and everything of mindfulness, this can lead to falling into a variety of errors. The practitioner can assume that they are following instructions and are using bare or nonjudgmental awareness, or seeing things with the attitude of nonduality, yet can in actuality be drifting into the extremes of either self-indulgence or passivity. The former of these errors can be summarized as the delusion that: "As long as I'm mindful, whatever I do is OK." This view has a parallel in the Antinomian heresy, the doctrine that: "by faith and the dispensation of grace a Christian is released from the obligation of adhering to any moral law" (Collins English Dictionary 2014). The other extreme, of passivity, is the danger of becoming an abstracted or dissociated "watcher" of experience. This psychological distancing or numbing is a destructive misunderstanding of the principle of detachment. Both of these extremes can have numerous negative effects, including social conflict, alienation, and depression. On its own, this rudimentary quality of sati can be called "mechanistic mindfulness."

Second, sati-sampajañ̃a means mindfulness and clear comprehension. It is also translated as mindfulness and full awareness or intuitive awareness (Sumedho 2014a). This term describes the psychological stance wherein the object or action is appreciated within its context of time, place, and situation. The precursors to the current experience and its possible consequences are included. This broadening and deepening of the view intrinsically include an appreciation of the practitioner's attitudes and the impact that any actions they are involved in will have upon themselves and others. Sati-sampajañña, mindfulness and full awareness, thus naturally incorporates ethical concerns, these being influential according to the degree to which full attunement to the time, place, and situation is established, as well as the degree to which self-interest has been recognized as obstructive. In addition, the greater the development of mindfulness and full awareness is, the more the elements of kindness and compassion will be invoked, and the more apparent the appropriateness of any action will be in terms of it leading to the well-being of oneself or others. This can be called right mindfulness, as per Monteiro et al. (2015) (p. 3), or more colloquially, "informed mindfulness."

Third, sati-pañ $\tilde{a} \bar{a}$ means mindfulness conjoined with wisdom and is regarded as the quality that leads to the full blossoming of human well-being. The term describes 
the psychological standpoint wherein all experience, inner or outer, is viewed as patterns of organic change arising and passing within consciousness. This process involves the examination of all experience in a phenomenological manner. The practitioner trains themselves to receive the flow of experience - sight, sound, smell, taste, touch, thought, volition, and emotion - in a nonjudgmental, unbiased way. This letting go of bias involves seeing the dependent nature and transparency of such categories as "like" or "dislike," "inside" or "outside," "mine" or "other's." In the letting go of such definitions as absolute realities, the practitioner realizes that what is experienced is not "the world" as a fixed and definite external reality, but rather it is rather "the mind's representation of the world." Insight meditation, vipassanā bhāvanā, is principally concerned with the development of this capacity.

To facilitate the development of such insight, the practitioner actively contemplates (a) the ever-changing nature of all experience, (b) the inability of any experience to remain permanently satisfying (Aidley 1998; Gertner 2003), and (c) that no experience can truly be said to be owned or to constitute a permanent self, as articulated by David Hume (2011; see Gopnik 2009):

There are some philosophers who imagine we are every moment intimately conscious of what we call our self... For my part, when I enter most intimately into what I call myself, I always stumble on some particular perception or other, of heat or cold, light or shade, love or hatred, pain or pleasure. I never can catch myself at any time without a perception, and never can observe any thing but the perception. When my perceptions are removed for any time, as by sound sleep, so long am I insensible of myself, and may truly be said not to exist... I may venture to affirm of the rest of mankind, that they are nothing but a bundle or collection of different perceptions, which succeed each other with an inconceivable rapidity, and are in a perpetual flux and movement.

The clear realization of the fluid, nonpersonal nature of all experience, which on account of its fleeting nature cannot permanently satisfy, results in what is termed in Pāli yathābhuta-ñannadassana, or "knowledge and vision of the way things are" or, in simpler terms, insight. This insight, based on a fully unbiased integration with the flow of experience, constitutes the fulfillment of the possibilities of mindfulness. This can be called "Noble" mindfulness, as per Monteiro et al. (2015) (p. 3), or holistic mindfulness (Amaro 2013) as it constitutes the consummation of the mind's potential in this respect. When fulfilled to its ultimate capacity, this constitutes enlightenment, or realization of the Deathless, as noted above.
In the process of developing this quality of insight, schools of Buddhist meditation frequently use such terms as witnessing experience, being the detached observer of the mind or being the one who knows. Although such terms are by no means incorrect, they can easily incline the attitude of the practitioner toward experiential avoidance, spiritual bypassing, and passivity. Experience has shown that the use of alternative forms of expression such as unentangled participation or selfless interaction serves to describe vipassanā in a more accurate way. For, although the depth of detachment realized in vipassana $\bar{a}$ is maximized, it is partnered by a fully integrated attunement to time and place and situation.

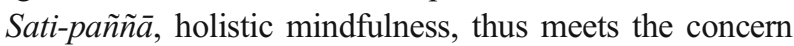
raised at Monteiro et al. (2015) (p. 8) that: "a poor grasp of concepts such as bare awareness, non-judgmental awareness, non-duality, and so on are likely to misguide the participants into bypassing their experience rather than connecting with it." If the mindfulness is genuinely holistic, then there will necessarily be a skilful connecting and working with experience, rather than avoidance of it or a reckless absorption into it. Most significantly to the discussion on ethics, according to Theravāda Buddhist philosophy, the more firmly that holistic mindfulness is established, the more the individual effortlessly inclines to acting in an honest, harmless, and modest way. There is no imposition of a moral code from outside; furthermore, it is the disposition of the practitioner to act in ways that bring themselves and others the greatest ease and that cause minimum distress.

At this stage of the development of mindfulness, the mind is indeed being actively encouraged to be nonjudgmental, as per Kabat-Zinn's (2004) definition, but this nonjudgmentalism refers to refraining from habitual harsh and absolute judgments of good and "evil," right and wrong. It does not mean foolishly going against common sense. Is a person being judgmental if they put their right shoe on their right foot? No, they do so because putting it on the left brings discomfort and difficulty. They do not look at their left foot as evil or bad, it is simply the incorrect foot for a shoe shaped for the right.

Monteiro et al. (2015) (p. 6) stated that Titmuss (2013) "expressed concerns that by defining mindfulness as a form of non-judgmental awareness, not only were there risks of reinforcing passivity and maintaining oppression but also the very intention of the practice as one that transforms greed, hatred, and delusion is lost." Titmuss pointed to the dangers of grasping the concept of being nonjudgmental in a foolish way and misusing it to justify self-centered habits and preferences, or being complicit with destructive situations and the structural violence of certain relationships or institutions.

Sati-pañ̃̃a enables the individual to make wise distinctions both for everyday functions like putting on shoes, as well as for significant life choices (such as whether to join the army or not) and interpersonal interactions (such as whether to tell the 
truth or not), yet in these latter cases without the harsh judgmentalism that is so psychologically destructive. Just as one chooses the left shoe for the left foot, with holistic mindfulness, one inclines to choosing the action that is going to bring most benefit and least harm to oneself and others. It also provides a person with the bravery to act and oppose oppression yet without harboring attitudes of hatred or ill-will.

Chah (2011) regularly used a particular simile to illustrate the relationship between these three dimensions of mindfulness: sati (mechanistic mindfulness) is like the hand which picks up an object; sati-sampajañña (informed mindfulness) is like the arm that moves the hand to the appropriate place and at the appropriate time; sati-pañ̃ $\bar{a}$ (holistic mindfulness) is like the body to which the arm is connected - it is both the life source and the means of integration and direction for the entire system.

Currently, the word mindfulness is used unsystematically to refer to all these three dimensions, so it should come as no surprise that there is some confusion. This could be avoided if we regard the mindfulness of the sniper as comparable to that of a cat or a squirrel; it is mindfulness, but of the most rudimentary nature. The mindfulness that encourages us to attune to situations skillfully and to live as a benevolent and responsible member of society is of a different order. Lastly, the mindfulness that enables us to be totally at ease and to remain emotionally balanced amid life's every vicissitude is the embodiment of inner security and freedom, which is of another order altogether.

\section{The Role of Ethics in Human Well-Being}

The subject of ethics receives frequent and substantial mention in Monteiro et al. (2015). For example, on page 6: "The often-fierce criticisms of MBIs have focused on a single theme: the omission of immediately apparent ethics in the teaching of MBIs." This point is repeated on page 8: "The most severe criticisms leveled at MBIs are that the model of contemporary mindfulness is incomplete because of the absence of explicitly taught ethics (Purser and Loy 2013; Titmuss 2013)."

The response to this central issue concerning mindfulnessbased interventions (MBIs) from the founder of mindfulnessbased stress reduction (MBSR) is significant. Monteiro et al. (2015) (p. 8) stated: "Reflecting on the choice to keep the teachings of ethics implicit, Kabat-Zinn (2011) states that each person carries the responsibility both personally and professionally to attend to the quality of their inner and outer relationships... At the same time, he indicates that this must be supported by 'explicit intentions regarding how we conduct ourselves both inwardly and outwardly' (p. 295)." Further, "Kabat-Zinn (2011) responds to earlier concerns about the exclusion of ethics by indicating that personal and professional ethical guidelines are intrinsic to the delivery of $\mathrm{MBI}$ programs. He also argues that because there is a societal tendency to be incongruent with respect to inner and outer moral stances, an implicit teaching of sīla is preferable."

Kabat-Zinn's words here seem particularly carefully chosen. They are balanced on a tightrope between his acknowledged respect for the source of MBSR - "I have always used 'mindfulness' as a placeholder for 'the Dharma"" (Kabat-Zinn 2013) - and his intention to make MBSR as accessible to as broad a field of people as possible.

However, what guidelines he gives are, from the traditional Buddhist perspective, significantly vague. The statements that "each person carries the responsibility both personally and professionally to attend to the quality of their inner and outer relationships," and that one should have "explicit intentions regarding how we conduct ourselves both inwardly and outwardly," could comfortably be assigned to the fictional characters of Tony Soprano or Walter White. Of even more concern is the statement that "because there is a societal tendency to be incongruent with respect to inner and outer moral stances, an implicit teaching of sìla is preferable." This seems to state that, because there is a disparity between the ideals people hold and what they actually do, it is best not to talk about the subject at all. If this is a correct interpretation of the comment and again, from a traditional Buddhist standpoint, this is a very dubious principle upon which to structure a pedagogical approach and a system of would-be beneficial psychological practices.

It is readily acknowledged that within the broader domain of ethics, there are labyrinths of cultural mores, tangled thickets of moral relativism, and minefields of emotional reactivity. Monteiro et al. (2015) explored many of the issues thoroughly and effectively, so the comments here will focus upon an explanation of the traditional Buddhist perspective on ethics, specifically the approach of the Theravāda or Southern school, and offer these for consideration in relationship to the development of MBIs in the fields of education, health care, psychological well-being, business, and governmental responsibility.

\section{Two Kinds of Ethics}

In addressing this area, as stated in Monteiro et al. (2015) (p. 10), some suppositions are being made: "These extensions of Buddhist concepts make some meta-ethical assumptions - for example, that ethics are not entirely relative or tradition-specific, that they can have some universal application across times and cultures which in turn rests on an understanding of human nature as being universal." This is an accurate representation of the traditional Buddhist view, with respect to some ethical norms, but it is important to note that there is a distinction made between two types of sīla. 
First, pakati-sìla means intrinsic or natural sīla. According to the philosophy of the Theravāda Buddhist school, all acts of killing, stealing, sexual misconduct, and lying will necessarily cause painful consequences for the doer - great or small according to circumstancesirrespective of place, time, culture, or social mores. Arguments describing the background to this, specifically for the case of killing, are made effectively by Gethin (2004). A related dialogue on the same issue has recently been conducted between Bodhi (2014) and Thanissaro (2014a, b). Both Gethin and Thanissaro argue very effectively that all acts of killing are antithetical to Buddhist silla, as elucidated in the Pali Canon, and it is suggested that this understanding be used as the substratum for the ongoing discussions on ethics.

Second, pañnatti-sīla is prescribed or socially agreed sīla. This category comprises the multitude of legally, culturally, and religiously conditioned ethical forms adopted by different societies and faiths. Such prescribed ethics would include the correct way to bow to a shrine, which side of the road to drive on, which day is a holy day, how to behave at dinner parties, how to write an academic paper, and how a Buddhist monastic should wear their robes.

As above, we again take note of the comment by Monteiro et al. (2015) (p. 12): "It is also important to investigate the subtle ways in which the very teaching of a philosophy derived from an Eastern culture is already a propagation of a set of valued virtues or an 'action-guide' based on a different worldview." And, again, this point is taken in addressing the very different way in which ethical norms and morality are regarded in the East and in the West. The Judeo-Christian conditioning of right and wrong as absolutes does not apply in the traditional Buddhist view of reality. Whereas the biblical tradition takes the form of commandments, literally, "Thou shalt...," despite the secularization of the West, the moral diktat from above and the fear of Mortal Sin still have their psychological effect on the Western weltanschauung. In contrast, the Buddhist understanding of the fundamental nature of experience can best be summarized as "original purity." In the words of the King of Thailand, in a BBC interview (Handley 2006, p. 273): "Usually the one who practices politics in any doctrine wants to get on the top. If you think of Buddhism, one does not want to be on the top, because there is no top, there's no bottom. It is just pure purity.... There is the original purity, which has been spoiled by, or covered by, what we call sin. The original thing that is light, is beautiful."

\section{A Method of Training}

As with the Buddha's formulation of the Four Noble Truths, he takes a pragmatic versus a dogmatic, idealistic approach to issues of behavior and to sīla. The Pāli word that is usually translated as precept or rule is sikkhappada. This literally means a "method of training" and when an individual commits themselves to living according to the Five Precepts, the basic moral code of the Traditional lay Buddhist, they recite the phrase meaning: "I undertake the method of training of refraining from taking the life of any living being..." The principle is thus that one knows one needs to train oneself and that not only one will do one's best but also one knows that one is going to make mistakes. The method of using such mistakes, in the words of the Buddha, is described thus: "It's a cause of spiritual development when, seeing one's transgression as such, one makes amends and exercises restraint in the future" (D 2.100).

If the approach toward ethics is more pragmatic than dogmatic, it shifts the perspective from telling people what they should do to that of helping us to do ourselves and others a favor. In Buddhist tradition, it is entirely up to the individual as to whether or not they draw close to the religion and whether they adopt the Five Precepts as guidance for skillful living. There is no external authority that condemns or rewards; instead, one is seen as simply being the recipient of the pleasant and painful results of one's own choices. As it reads in the scriptural text (A 5.57): "A woman or a man, a householder or a monastic, should often reflect thus: 'I am the owner of my action, heir to my action, born of my action, abide supported by my action; whatever action I do, for good or for ill, of that I will be the heir." This approach shifts the responsibility for well-being firmly into the individual's own hands. A person is not called good because of adhering to an external system of mores, or bad because they defy them, rather it is recognized that if a person does not want to get burned, they would be wise not to stick their hand into the fire.

The introduction of explicitly stated that ethics into MBIs therefore need not be made under the banner of: "The Buddha tells you that you should..."; indeed, to do so would run quite counter to the spirit of the Buddha's methodology. Instead, the suggested ethical standards would be more appropriately presented as follows: Here are some guidelines for behavior and speech that might help you to reduce stress and live more comfortably; if you are interested you can try them out and see what their effects are.

\section{The Role of Intention}

In Buddhist tradition, when considering the subject of action and its results, the intention behind the action is regarded as being of paramount significance. At one point the Buddha even baldly states that (A 6.63.5): "Intention I call action (kamma)." According to this understanding, if a person unknowingly treads upon an ant and kills it, the psychological 
effect on the person will be much less negative than if they trod on it deliberately. The monastic rule (vināya) is based upon this principle. Thus, in the analysis of the vast majority of monastic sikkhappada, there is the allowance clause that: "if there was no intention, it was not an offence."

Monteiro et al. (2015) generally addressed the role of intention in an accurate and comprehensive way, although in one instance, Gethin was quoted on this subject in a somewhat misleading fashion. Monteiro et al. (2015) (p. 10) stated: "However, Gethin is emphatic that the final arbiter of the morality of an action is the degree to which the agents of such acts are aware of the quality of their own mind." This statement can be read to mean that Gethin is stating that as long as the person feels fully aware of what they are doing, it thereby becomes a moral act. This view, from the traditional Theravāda Buddhist perspective, harks back to the selfindulgent strand of mechanistic mindfulness described above and can be illustrated by the rudimentary mindfulness of the sniper. This view can be summarized as the understanding that: "As long as I'm mindful, whatever I do is OK," which is contrary to what Gethin proposed.

In contrast, Gethin (2004) wrote, “. . . the only criterion for judging whether an act is 'moral' (kusala) or 'immoral' (akusala) in Indian systematic Buddhist thought is the quality of the intention that motivates it." And further: "For the Theravāda Buddhist tradition there is in the end only one question one has to ask to determine whether an act is wholesome (kusala) or unwholesome (akusala): is it motivated by greed, hatred, and delusion, or is it motivated by nonattachment, friendliness, and wisdom." "In the particular case of killing a living being, I have argued that for Theravāda Buddhist thought - and probably mainstream Indian Buddhist thought - intentionally killing a living being can never be considered wholly an act of compassion [and therefore moral, kusala]." Therefore, according to Gethin, "the final arbiter of the morality of an action is" not "the degree to which the agents of such acts are aware of the quality of their own mind," but instead whether "the quality of the intention that motivates it" is wholesome or unwholesome.

Monteiro et al. (2015) (p. 12) commented on this issue: "Buddhist ethics has contingencies for aggressive action; however, Buddhist scholars question how many could act with clear comprehension of their own motivation and the greater good. This point speaks strongly to the need for MBIs to develop a robust curriculum that cultivates clear comprehension of the practitioner's motivations and intentions, particularly in domains where moral action is a complex decision-making process." As commented above, if mindfulness is being developed to its informed (sati-sampajañna) and holistic (sati-pañ̃̃a) levels, the factors of wholesomeness and unwholesomeness are understood to be intrinsically brought into play and to thereby influence choices of action. The framework of the Five Precepts can thus be considered as conveniently systematizing that what, in Theravāda Buddhist philosophy, is seen as the natural disposition of the person when mindfulness in them is being developed to its fullest extent. The Five Precepts are the following: (1) I undertake the precept to refrain from taking the life of any living creature, (2) I undertake the precept to refrain from taking that which is not given, (3) I undertake the precept to refrain from sexual misconduct, (4) I undertake the precept to refrain from lying, and (5) I undertake the precept to refrain from consuming intoxicating drink and drugs which lead to carelessness.

\section{Shame and Guilt}

In any examination of behavior in relation to issues of ethics, the functions of shame and guilt need to be considered. In the Theravāda Buddhist perspective, shame or moral sensitivity (hiri-ottappa) is regarded as a sign of mental health. It is the emotional pain felt by a responsible person when they, for example, tell a lie or deliberately cause harm to another. It is regarded as a concomitant of physical pain that, similarly, usefully serves to protect the body.

Guilt, as the word is used in this context, indicates an egocentered destructive attitude, mingled with self-hatred that always has negative consequences. The Pāli word for guilt is aparädha, although this has more the meaning of having been responsible for a crime, rather than the self-created inwardly directed destructiveness that is so common in the West. The latter is what is felt when the ego ruthlessly co-opts hiriottappa.

Interestingly, once again, here is an instance of "the subtle ways in which... a philosophy derived from an Eastern culture is... based on a different worldview." The absence of a word in the Buddhist lexicon to specifically describe this psychological quality illuminates the effects of the Judeo-Christian worldview. At the Harmonia Mundi conference (1989), HH the Dalai Lama was asked by one of the attendees how to deal with self-hatred. His Holiness cautiously asked him if he had committed some crime that haunted him. His interlocutor replied, "No! I'm a very honest person; I just hate myself." The Dalai Lama then looked puzzled and went into a huddle with his translator, Thubten Jinpa, who had spent many years studying in the West, at Cambridge University. The translator quickly explained to His Holiness the prevalence of such groundless attitudes of self-loathing in the West; emerging from the whispered consultation, the Dalai Lama remarked: "This is most unfortunate, but it is just a minor mental irritation; ignore it and it will go away." Surprised laughter erupted throughout the hall.

If the role of hiri-ottappa in the development of well-being is understood in this way, it can be freed from its co-option by ego-centered attitudes and accordingly can function in an extremely useful way. If ethics were to be more explicitly articulated in MBIs, this understanding of the skillful use of 
hiri-ottappa would increase the effectiveness of their employment. This is the case since, with ethical sensitivity being consciously increased, informed and holistic mindfulness would enable the individual to process those feelings of hiriottappa appropriately. Just as if one is mindful of physical pain in a wise and nonjudgmental way, that pain can be handled and its useful signals read accurately. So too, with the emotional pain of hiri-ottappa, it helpfully informs one of the effects of one's actions and how best to proceed for maximum benefit, for both oneself and others.

According to the traditional Theravāda Buddhist perspective, the more this process is actualized with holistic mindfulness, the more the effect of a person's actions on others becomes apparent. The practice of ethics thus becomes enhanced out of compassion for others, rather than through an external agency, or the internal narrative of the super-ego, telling us that we should or should not act in certain ways. In this manner, our way of living helps others to feel safe around us - in the Theravāda Buddhist tradition this is called abhayadāna - the gift to others of freeing them from fear. The current movement toward involving compassion specifically in mindfulness trainings (e.g., Germer 2009; Gilbert 2010) can thus be seen as being deeply related to the matter of ethics. The wholesome actions and speech of an individual are not only compassionate and of benefit to themselves but are also acts of kindness and compassion toward others.

\section{A Methodology for the Fulfillment of Well-Being}

One of the psychological mechanisms described in the Theravāda Buddhist scriptures (A 10.2) purports to outline a natural and causal process through which a person can develop, upon the basis of silla, to the comprehensive well-being of spiritual emancipation, known as liberation or enlightenment. The text describes how, through living ethically and responsibly, freedom from remorse arises; based on that freedom from remorse, self-respect and joy arise, leading to physical ease, the relaxation of the body; that physical ease then conditions profound contentment, which in turn leads to mental focus, concentration (samādhi); that mental focus leads naturally to insight, wisdom, which in turn conditions a letting go, an unentangled participation in the field of all experience; this in turn leads to liberation, meaning complete psychological well-being.

The development of holistic mindfulness and the consequent establishment of ethical standards of living are thus seen, from the Theravāda Buddhist perspective, to be the basis upon which this causal process is founded. They are the firm footing upon which this sequence of developmental rungs is planted.

The description here of the process is somewhat linear; however, it does not refer to a single trajectory, directed to a grand enlightenment experience at the end; rather, it outlines the pathway of an individual's mind states, moment by moment. In addition, the various elements of the process mutually reinforce each other along the way, for example, better concentration helps one to be more mindful, more mindfulness improves one's ethical standards, more careful standards lead to a greater freedom from remorse which leads to better concentration, and so forth. The interrelatedness of factors in this causal process functions much as do the factors of the Eightfold Path, as described in Monteiro et al. (2015) (p. 2): "In Buddhist traditions, the Eightfold Path is often depicted as a wheel with eight spokes - this helps to communicate the important idea of the interdependence of each of the domains."

It is a theoretical model that is for consideration and, as with all Theravāda teachings and practices, it is to be explored as per the protocols of the Kalama Sutta, as cited above. It needs to be tested out for oneself and explored to see if it indeed describes the pattern of things, and then if its application is of benefit. To enter into such exploration, which could be described as an in-depth MBI, it might be beneficial to frame the process using the classical threefold model of knowledge as found in the Pāli texts. In this classical model, the three elements can be summarized as follows: Pariyattiacademic study; $P$ a ipatti-contemplative practice; and Pa ivedha-realization. In this instance, the academic study would be one's intellectual familiarization with the list of related factors; the contemplative practice would be the effort to see whether the pattern worked as described and if these factors were indeed interrelated, and if it was of benefit to look at things in this way; the realization would be the well-being that arose from the development of the factors of this causal process.

The description of MBIs, as presented by Monteiro et al. (2015), defined three contributing factors to the process. These three, in a slightly different configuration, seem to parallel this threefold model of knowledge. When compared to Fig. 1 in Monteiro et al. (2015), pariyatti (study) aligns with [2] the intellectual grasp of Buddhist philosophy, "the understanding of how we experience the flow of events in our body/mind." Pa ipatti (practice) aligns with [1] "contemplative practice." While pa ivedha (realization) addresses [3] actualizing the "shift away from experiential avoidance."

\section{Wisdom and samādhi Develop sīla}

In the teaching and practice of Buddhism in the West, across all traditions, it is commonly found that there is initially little interest in the subject of ethics. The use of meditation as a way to calm the mind, coupled with the development of wisdomwhether through the practices of the Theravāda (Southern) or Mahāyana (Northern) Buddhist traditions - is the clear priority for interested Westerners. 
In the traditional methodologies of Buddhism in Asia, the practices of generosity (dāna) and ethics, or virtue (sìla), are regarded as the sine qua non of spiritual development. It is a given, backed up by numerous statements by the Buddha (e.g., D 31.3-8 in relation to lay-life and M 51.14 in relation to monastic life) that any significant growth toward psychological well-being depends on a foundation of wholesome ethical conduct. In this light, when Ajahn Chah came to visit the West in the late 1970s, his close students found it strange that he emphasized meditation (samādhi-bhāvanā) and wisdom (pañña) in his teachings to the Western audience yet seemed to mention silla sparingly. Ajahn Chah explained that it was clear to him that there was a disinterest in, even a strong resistance to, the concept of sila in the West as it seemed to go counter to popular ideals of freedom. He was prepared to respect the fact that this was where the students were starting from because he felt that, in due time and with experience, they would see for themselves that by ignoring wholesome ethical standards they were only causing themselves trouble. He considered that it was more effective for individuals to learn such truths for themselves, rather than to take it as received knowledge from some religious authority.

It was plain to him that Westerners practiced meditation with great sincerity-even remarking that he could never get his monks and nuns to sit so still and keep so silent as the Westerners on a 10-day retreat-however, it was also clear that the students were not living according to wholesome standards of ethical conduct between retreats. Breiter (2004) recounted Ajahn Chah as saying, "The approach many people had to meditation was like a thief who after he gets caught hires a clever lawyer to get him out of trouble. Once he is out, he starts stealing again. [Ajahn Chah] also compared it to a boxer who gets beaten up, nurses his wounds, and then goes to fight again, which only brings him fresh wounds. And this cycle goes on endlessly. The purpose of meditation is more than just calming ourselves from time to time, getting ourselves out of trouble, but seeing and uprooting the causes which produce trouble and make us not calm to begin with." This process of seeing and uprooting such causes is understood, in traditional Buddhist practice, to be realized through the development of both informed and holistic mindfulness (sati-sampajañna and sati-pañña). The individual learns through their own experience and wise reflection (yonisomanasikāra) that if one behaves dishonestly, self-indulgently or cruelly, the mind will remember those events and their causes. If there is a wish to not have such memories to deal with, the simplest approach is seen to be to refrain from such acts in the first place. This might be considered to be an overly simplistic approach and one that imposes unwished for restrictions on the individual; however, it can also be regarded as a pragmatic way to fulfill a person's aspiration to comprehensive well-being. It is safe to presume that most people would not regard it as an imposition upon their freedom to have it pointed out that the left shoe is designed to fit the left foot, not the right.

\section{Conclusion}

Monteiro et al. (2015) (p. 12) stated, "It is tempting to claim that contemporary mindfulness has evolved beyond its Buddhist origins or that Buddhist traditions do not have a proprietary claim on mindfulness. However, that begs the question of what model then underpins and guides the process of the MBIs. The path through this tangle of concerns lies in a continuing dialogue that mutually challenges and clarifies concepts and practices as both traditional and contemporary mindfulness evolve." The intent of this present paper has been to explicate principles embodied in the traditional Buddhist teachings, specifically those of the Theravāda school, which might serve to inform this continuing dialogue.

The aim of this paper was specifically (1) to elucidate the pragmatic versus dogmatic approach of the Buddha in his teachings on psychological transformation, (2) to clarify the traditional understanding of the term mindfulness and its various layers of meaning, and (3) to examine the role of ethics in human well-being, as it is understood from a traditional Buddhist viewpoint.

When reflecting from that viewpoint on the current range of mindfulness programs operating around the world, it seems that the serious consideration, by those delivering MBIs, of all three of these areas could bring many benefits. The societies of the West are generally secularized, with representations of some strongly held religious beliefs. The nondogmatic approach of Buddhism can be seen to fall in the fertile littoral zone between the doctrinaire religiosity of one camp and the staunch scientific materialism of the other. The more that these pragmatic principles of traditional Buddhism are appreciated, the more that those delivering MBIs might feel comfortable in consciously drawing upon them and recommending them as resources to their clients. To traditional Buddhists, the classical teachings can be freely drawn upon and practiced by anyone, of any philosophical persuasion, without any expectation of commitment. For example, elsewhere, I have stated (Amaro 2012): "The intent... is to provide methods, techniques and principles that anyone can apply within the sphere of their own life - whether one is a Humanist, a Christian, a Communist, a Buddhist or a follower of any other belief system. Nothing provided here is directed to trying to convince anyone that Buddhism is right, or to cause anyone to waiver in their own faith, whether it's Christianity, Judaism, Islam or any other spiritual path. Nor is the intention to make everyone... into a Buddhist. What is presented here is simply a set of methods and principles anyone can use to make their life better." 
From the traditional Theravāda point of view, the vigorous debate on the issue of ethics could be well informed by two distinct factors. The first of these is the clarification of the different grades of mindfulness, as described in the traditional teachings. The second factor is the various points on ethics outlined above-particularly the aspect of the sikkhapada being methods of training rather than absolute moral imperatives, and the understanding of hiri-ottappa as highly beneficial ethical sensitivity, as opposed to a toxic guilt. The pragmatic approach to ethics here versus an idealistic and pedantic one is, once more, the key point.

It is fully understandable why the founders of MBSR and MBCT decided to articulate their therapeutic programs avoiding all reference to the Buddhist origins of some of their methodologies. The secularized expression of the trainings might well have rendered them accessible to a wide range of people, but, again from the traditional Theravāda point of view, there are considerable disadvantages in that too. First, if the Buddhist origins of the practices involved in MBIs were explicitly acknowledged, that would make the vast range of philosophical teachings and practices of Buddhism more readily accessible to those participating; furthermore, it would grant those origins their appropriate credit. Second, if those Buddhist origins were more customarily acknowledged and if the nondogmatic nature of the Buddhist approach was employed, the usefulness of living according to a defined standard of ethical responsibility, such as the Five Precepts, could be introduced into MBIs with impunity. Such an introduction could be regarded not as a limiting imposition from a traditionalist religious form but rather as an extension of the role of compassion in mindfulness practice.

If maximizing well-being is the aim of a person's efforts, although compassion toward themselves is of central importance, the relationship to the human group within which they operate needs to be considered as well. The development of a more holistic mindfulness would not only support the growth of self-compassion and thereby an individual's own wellbeing, but it would also lead toward cultivating compassion for others. As compassion for self and others developed, it would naturally lead to an inclination to live by a wholesome ethical standard. This is so because, by living wholesomely, a person frees the mind from having to remember unskillful and harmful acts, and that freedom from remorse leads to a profound self-respect and ease, resulting in a comprehensive quality of well-being. The inclination toward kindness and compassion for others also contributes to increasingly wholesome ethical standards since, if compassion is a primary emotion in the relationship, lying, stealing, harming, or taking sexual advantage of another would be anathema.

In this way, according to the traditional Theravāda point of view, holistic mindfulness is regarded as the basis and methodology whereby a fullness of well-being is actualized. It supports and is supported by such wholesome qualities as kindness and compassion (mettā and karun $\bar{a})$ as well as the other Brahma Viharas, as is quoted of McCown in Monteiro et al. (2015) (p. 10): "The Brahma Viharas, which form a framework of virtue ethics, could point to behavioral focus on certain actions and activity which promote moral action." A conscious and committed observance of the Five Precepts can serve effectively as a vehicle enabling the transforming power of mindfulness and compassion to be fulfilled.

The perspectives outlined here should not be regarded as a claim that Buddhist traditions have a proprietary claim on mindfulness. Nor should the behavioral standards described by the Five Precepts even be regarded as specifically Buddhist in the comments on pakati-silla. All the comments, as well as the philosophies and practices described here, are offered in the effort to inform the continuing dialogue. May these perspectives be carefully considered and all that is worthy within them be put to use for the benefit of all.

\section{Abbreviations}

$\begin{array}{ll}\text { A } & \text { Anguttara Nikaya } \\ \text { D } & \text { Digha Nikaya } \\ \text { Dhp } & \text { Dhammapada } \\ \text { M } & \text { Majjhima Nikaya } \\ \text { S } & \text { Samyutta Nikaya }\end{array}$

\section{References}

Aidley, D. J. (1998). The physiology of excitable cells. Cambridge: Cambridge University Press.

Amaro, A. (2012). Finding the missing peace: a primer of Buddhist meditation. Hertfordshire: Amaravati.

Amaro, A. (2013). Mindfulness and its supportive friends. Rome: Sapienza University. Paper presented at the First International Conference on Mindfulness.

Analayo, B. (2003). Satipatthana: the direct path to realization. Cambridge: Windhorse Publications.

Analayo, B. (2011). Right view and the scheme of the four truths in early Buddhism: the Sa yukta-āgama parallel to the Sammādi hi-sutta and the simile of the four skills of a physician. Canadian Journal of Buddhist Studies, 7, 11-44.

Bodhi, B. (2014). War and peace: a Buddhist perspective. Inquiring Mind, 30(2).

Breiter, P. (2004). Venerable father: a life with Ajahn Chah. New York: Paraview Special Editions.

Chah, A. (2011). The collected teachings of Ajahn Chah. Northumberland: Aruna Publications.

Collins, U. K. (2014). Collins English dictionary. 12th ed. HarperCollins.

Germer, C. K. (2009). The mindful path to self-compassion. New York: Guilford.

Gertner, J. (2003). The futile pursuit of happiness. New York Times.

Gethin, R. (2004). Can killing a living being ever be an act of compassion? The analysis of the act of killing in the Abhidhamma and Pali commentaries. Journal of Buddhist Ethics, 11, 167-202. 
Gilbert, P. (2010). The compassionate mind. Oakland: New Harbinger Publications.

Gopnik, A. (2009). Could David Hume have known about Buddhism? Charles Francois Dolu, the royal college of La Fleche, and the global Jesuit intellectual network. Hume Studies, 1\&2, 5-28.

Halliwell, E. (2014) Mindfulness: has it been hijacked by business or can it change lives? Retrieved from: http://www.theguardian.com/ sustainable-business/mindfulness-hijacked-business-parliamentaryinquiry.

Handley, P. M. (2006). The king never smiles: a biography of Thailand's Bhumibol Adulyadej. New Haven: Yale University Press.

Hume, D. (2011). A treatise of human nature. Oxford: Oxford University Press.

Kabat-Zinn, J. (2004). Wherever you go, there you are: mindfulness meditation for everyday life. New York: Hyperion.

Kabat-Zinn, J. (2011). Some reflections on the origins of MBSR, skillful means, and the trouble with maps. Contemporary Buddhism, 12(1), 281-306.

Kabat-Zinn, J. (2013). Mindfulness, meditation, and health: transformation and healing at the confluence of science and dharma. Rome: Sapienza University. Paper presented at the First International Conference on Mindfulness.
Monteiro, L. J., Musten, R. F., \& Compson, J. (2015). Traditional and contemporary mindfulness: finding the middle path in the tangle of concerns. Mindfulness, 6, 1-13.

Purser, R., \& Loy, D. (2013). Beyond McMindfulness. Huffington Post. Retrieved from: http://www.huffingtonpost.com/ron-purser/beyondmomindfulness_b_3519289.html.

Rhys Davids, T.W., \& Stede, W. (1921-1925). The Pali text society's Pali-English dictionary. Pali text society. Retrieved from: http://lirs. ru/lib/dict/Pali-English_Dictionary,1921-25,v1.pdf.

Sumedho, A. (2014a). Ajahn Sumedho: the anthology (Vol. 4: The sound of silence). Hertfordshire: Forest Sangha Publications.

Sumedho, A. (2014b). Ajahn Sumedho: the anthology (Vol. 5: The wheel of truth). Hertfordshire: Forest Sangha Publications.

Thanissaro, B. (2014a). War and peace, a Buddhist perspective: a letter to the editor from Thanissaro Bhikkhu. Inquiring Mind, $30(2)$.

Thanissaro, B. (2014b). War and peace, a Buddhist perspective: a postscript from Thanissaro Bhikkhu offering six observations on Ven. Bodhi's response. Inquiring Mind, 30(2).

Titmuss, C. (2013). The Buddha of mindfulness. The politics of mindfulness. Retrieved from: http://christophertitmuss.org/blog/? $\mathrm{p}=1454$. 